\begin{tabular}{|c|l|}
\hline Title & What is the Major Source of Business Cycles: Spillovers from Land Prices, Investment Shocks, or A nything Else? \\
\hline Author(s) & Shirota, Toyoichiro \\
\hline Citation & Discussion Paper, Series A, 323, 1-20 \\
\hline Issue Date & 201803 \\
\hline Doc URL & http:/hdl.handle.net/2115/68511 \\
\hline Type & bulletin (article) \\
\hline File Information & DPA 323.pdf \\
\hline
\end{tabular}

Instructions for use 
Discussion Paper, Series A, No.2018-323

What is the Major Source of Business Cycles:

Spillovers from Land Prices, Investment Shocks, or Anything Else?

Toyoichiro Shirota

March, 2018

Faculty of Economics and Business

Hokkaido University

Kita 9 Nishi 7, Kita-Ku, Sapporo 060-0809, JAPAN 


\title{
What is the Major Source of Business Cycles: Spillovers from Land Prices, Investment Shocks, or Anything Else?
}

\author{
Toyoichiro Shirota ${ }^{\dagger}$
}

March, 2018

\begin{abstract}
Some recent studies argue that spillovers from land prices into the aggregate economy are the crucial drivers of business cycles. Other studies stress the importance of investment shocks at business cycle frequencies. This study evaluates these two strands of the literature in a single unified framework by estimating a New Keynesian dynamic stochastic general equilibrium model with a collateral constraint on investment financing. The results are twofold: (i) when these features are combined, neither shocks that drives most of land-price fluctuations nor investment shocks are the primary source of U.S. business cycles; and (ii) technology shocks play an important role in business cycles.
\end{abstract}

JEL classification: E32, E44

Keywords: Source of business cycles; Land price dynamics; Investment shock; Collateral constraint; Bayesian estimation;

\section{Introduction}

The discussion of what drives business cycles dates back at least to the classic studies of Kydland and Prescott [1982] and Sims [1980]. After the Great Recession in the late 2000s, debate over the source of business cycles has gained renewed attention, with a focus on the prominence of financial factors.

The literature, including Iacoviello [2005], Iacoviello and Neri [2010], and Liu, Wang, and Zha [2013], emphasizes the role of housing in the economy. By using dynamic stochastic general equilibrium (DSGE) models, these studies argue that spillovers from fluctuations in land (or housing) prices to other major variables are important sources of business cycles. Among them, Liu et al. [2013] report that land-price dynamics driven by the housing demand account for approximately 28 percent of the variation in output and 39 percent of the variation in investments in a neoclassical model with a collateral constraint. Although their simple and tractable model provides a good analytical starting point, it differs from typical business cycle models, such as Christiano, Eichenbaum,

\footnotetext{
${ }^{\dagger}$ Hokkaido University, toyoichiro.shirota "at" econ.hokudai.ac.jp; Kita 9 Nishi 7, Kita-ku, Sapporo, Hokkaido, 060-0809, Japan. I thank participants of the Asian Meeting of the Econometric Society in Hong Kong, Yonsei-Hokudai Joint Workshop, and Modern Economics Workshop at Hokkaido University for comments and suggestions. Discussion with Ippei Fujiwara was very helpful. All remaining errors are on my own. This work is supported by JSPS KAKENHI Grant Numbers JP16H06587.
} 
and Evans [2005] and Smets and Wouters [2007], which recent literature often uses to decompose for business cycles.

Other studies, represented by Justiniano, Primiceri, and Tambalotti [2010] and Justiniano, Primiceri, and Tambalotti [2011], use a standard business cycle model with a rich shock propagation mechanism. These studies demonstrate that shocks to the marginal efficiency of investment (MEI) -disturbances in transformation of investment goods into productive capital- are the primary source of fluctuations in output and investments in the U.S. ${ }^{1}$ Moreover, they argue that MEI shocks are proxies for financial factors because the estimated MEI shocks correlate highly with credit spreads. These studies reinforce the momentum toward developing models that enrich financial frictions. ${ }^{2}$ However, Justiniano et al. [2010] and Justiniano et al. [2011] do not consider spillovers from land-price fluctuations in the economy.

This study assesses these views within one unified framework and considers the shock that is a more relevant major driver of business cycles. To this end, we introduce land as a collateral asset in investment financing into a standard medium-scale DSGE model similar to Justiniano et al. [2011]. Because a medium-scale DSGE model suitably encompasses several views on the sources of business cycles, it provides a good experimental field for our objective.

In our estimated U.S. model, housing demand shocks determine most of the landprice fluctuations. They account for 75 percent of land-price fluctuations. However, they are not the primary source of business cycles. Housing demand shocks account for 14.8 and 23.0 percent of the variation in output and investment at business cycle frequencies. These numbers are approximately half of the numbers in the study of Liu et al. [2013]. Furthermore, MEI shocks account for only 2.6 and 6.7 percent of output and investment fluctuations, respectively. In contrast, technology shocks substantially affect macroeconomic variables at business cycle frequencies. 43.8 percent of the variation in output is attributable to technology shocks. ${ }^{3}$ Neither housing demand shocks nor MEI shocks are primary drivers of business cycles.

It is worth noting the reason why our results differ from those of Liu et al. [2013] and Justiniano et al. [2010]. Discrepancies in the studies of Liu et al. [2013] and ours stem from an assumption of the labor elasticity. The indivisible labor setting adopted in Liu et al. [2013] implicitly presumes an infinite Frisch elasticity of labor supply (e.g. Hansen [1985]), whereas we allow this elasticity to be finite and estimate it using data as in standard medium-scale DSGE models. The amplification effects of a positive housing demand shock will be dampened in our specification because a lower Frisch elasticity results in lesser substitution effects and greater income effects.

Discrepancies in the studies of Justiniano et al. [2010] and ours stem from the collat-

\footnotetext{
${ }^{1}$ Among the most influential studies in this area is Smets and Wouters [2007]. They argue that labor supply shocks primarily drive fluctuations in business cycles using an estimated medium-scale DSGE model. Justiniano et al. [2010] fault Smets and Wouters [2007]'s conclusions for depending on their definition of investment. As explained in data section, our investment data for estimation is the same definition of Justiniano et al. [2010].

${ }^{2}$ Wieland, Afanasyeva, Kuete, and Yoo [2016] summarize recent developments in this active area.

${ }^{3}$ Kaihatsu and Kurozumi [2014] also point out that technology shocks are the major source of business cycles using an estimated DSGE model.
} 
eral constraint and data used in estimations. A favorable MEI shock creates procyclical movements in consumption and investments but also creates countercyclical movements in stock prices because a MEI shock is a supply shock of capital accumulation. Through the collateral constraint, countercyclical movements in stock prices translate into credits. Because credits move procyclically in actual business cycles, MEI shocks fail to be a major source of business cycles when a model is estimated using credit data.

This study also relates to Brzoza-Brzezina and Kolasa [2013], who find the collateral constraint mechanism to be not crucial in fitting their model to the U.S. data. In our model, spillovers from housing demand through land prices are modeled explicitly and estimated using land price data; however, Brzoza-Brzezina and Kolasa [2013] consider only a collateral constraint on the value of capital. Hence, our results complement those of Brzoza-Brzezina and Kolasa [2013].

In the remainder of this paper, Section 2 provides an overview of our model. Section 3 presents our estimation method and data. Section 4 describes the estimation results and discusses their implications. Section 5 concludes the study.

\section{The model}

A standard medium-scale DSGE model is estimated that shares major features with Christiano et al. [2005], Smets and Wouters [2007] and Justiniano et al. [2011]. It contains nominal and real frictions that affect the decisions of economic agents. One key difference from models commonly used in the literature is the collateral constraint, a lá Kiyotaki and Moore [1997], whereby a lender has to post collateral to obtain external funds because of limited enforcement of financial contracts. We extend the model to include a collateral constraint on investment financing so that it can describe spillovers from the housing market into investments through land prices. ${ }^{4}$

The economy is populated by capital owners, households, final-goods producers, intermediate-goods producers and the government. Agents' problems and other constructions are as follows.

\subsection{Capital owners}

A representative capital owner receives utility from consuming $C_{c, t}$ in each period and invests in capital $K_{t}$ and land $L_{c, t}$, which are rented to intermediate-goods firms in competitive markets. Its objective is to maximize the following lifetime utility,

$$
E_{t} \sum_{s=0}^{\infty} \hat{\beta}^{s} \log \left(C_{c, t+s}-\gamma_{c} C_{c, t+s-1}\right),
$$

\footnotetext{
${ }^{4}$ Iacoviello [2005], Iacoviello and Neri [2010] and Liu et al. [2013] estimate DSGE models with a collateral constraint using US data. In the former two studies, a part of households face a collateral constraint on consumption. These models focus on the housing investment and have difficulties in reproducing positive co-movements between land prices and business investments. In the latter study, a capital owner faces a collateral constraint on business fixed investment. Since we examine the propagation of housing demand shocks through business investment, we adopt a modeling strategy similar to that of Liu et al. [2013].
} 
where $\gamma_{c} \in[0,1]$ is a parameter in the capital owner's formation of consumption habits. $\hat{\beta} \in(0,1)$ is a capital owner's subjective discount factor.

The capital owner confronts a flow of funds constraint and a capital accumulation process with quadratic investment adjustment costs that penalize deviations from steadystate investment growth, $\Delta \bar{I}$,

$$
\begin{aligned}
r_{t}^{k} K_{t-1}+r_{t}^{l} L_{c, t-1}+E_{t} \frac{B_{t}}{R_{t} / \pi_{t+1}} & =C_{c, t}+\frac{I_{t}}{A_{t}^{i}}+B_{t-1}+q_{l, t}\left(L_{c, t}-L_{c, t-1}\right), \\
K_{t} & =(1-\delta) K_{t-1}+\zeta_{t}\left[1-\frac{\Omega}{2}\left(\frac{I_{t}}{I_{t-1}}-\Delta \bar{I}\right)^{2}\right] I_{t},
\end{aligned}
$$

where $r_{t}^{k}$ and $r_{t}^{l}$ are rental rates of capital and land, respectively, $B_{t}$ is quantity of bonds, $R_{t}$ is the nominal gross return on bonds, $q_{l, t}$ is land prices in terms of final goods, $\Omega>0$ is a parameter of investment adjustment cost, $\delta \in(0,1)$ is a depreciation rate, and $\zeta_{t}$ represents an exogenous shock in the efficiency with which a final good is transformed into physical capital. Justiniano et al. [2011] call it an MEI shock. $A_{t}^{i}$ is an exogenous shock in investment-specific technology. The stochastic processes of all shocks are summarized in the latter part of this section.

Because of limited enforcement of financial contracts, the capital owner can raise funds up to a fraction $\theta_{t}$ of the total value of collateral assets,

$$
B_{t} \leq \theta_{t} E_{t}\left(q_{l, t+1} L_{c, t}+q_{k, t+1} K_{t}\right),
$$

where $\theta_{t}$ is the loan-to-value (LTV) ratio of pledged assets to collateral and $q_{k, t}$ is the real shadow price of capital. We call $\theta_{t}$ a collateral constraint shock and assume it is exogenous.

\subsection{Households}

Each household is continuously indexed as $j$ within a unit interval. It receives utility from consumption $C_{h, t}(j)$ and landholdings $L_{h, t}(j)$, and incurs disutility from labor supply $N_{t}(j) .{ }^{5}$ Each household is a monopolistic supplier of specialized labor. We presume that the household can access a portfolio of state-contingent securities, which ensures that, in equilibrium, consumption and asset holdings are identical for all households. The household's objective is to maximize the following lifetime utility,

$$
E_{t} \sum_{s=0}^{\infty} \beta^{s} v_{t+s}\left[\log \left(C_{h, t+s}-\gamma_{h} C_{h, t+s-1}\right)+\varphi_{t+s} \log \left(L_{h, t+s}\right)-\frac{N_{t+s}(j)^{1+\chi}}{1+\chi}\right],
$$

\footnotetext{
${ }^{5}$ As presented in a later section, the model is non-stationary because the growth rate of technological progress follows stationary AR(1) process. To ensure existence of a balanced growth path, we presume the utility function is log in consumption and separable with labor. Conditions for the existence of balanced growth path is discussed in King, Plosser, and Rebelo [1988].
} 
given a flow of funds constraint,

$$
C_{h, t}+q_{l, t}\left(L_{h, t}-L_{h, t-1}\right)+E_{t} \frac{B_{t}^{d}}{R_{t} / \pi_{t+1}}+T_{t} \leq W_{t}(j) N_{t}(j)+B_{t-1}^{d}+\Pi_{t}+Q_{t}(j),
$$

where $\beta \in(0,1)$ is a household's subjective discount factor, $\gamma_{h} \in[0,1]$ is a degree of habit persistence, $\chi \geq 0$ is an inverse of the Frisch's labor supply elasticity, $T_{t}$ are lump-sum taxes, $W_{t}(j)$ are real wages, $B_{t}^{d}$ are bond holdings, and $\Pi_{t}$ are per-capita profits accruing to households from the ownership of firms. $Q_{t}(j)$ are net cash flows from household $j$ 's portfolio of state-contingent securities. Following Kiyotaki and Moore [1997], households are more patient than capital owners. Therefore, $1>\beta>\hat{\beta}$. $v_{t}$ and $\varphi_{t}$ are exogenous shocks in intertemporal preference (patience) and household's taste for landholdings, respectively. Following Liu et al. [2013], we label the land taste shock $\varphi_{t}$ the "housing demand" shock.

Regarding the specification of labor disutility, Liu et al. [2013] adopt the indivisible labor setting of Hansen [1985] assuming that the Frisch's elasticity of labor supply is infinite, whereas standard medium scale DSGE models including Justiniano et al. [2010] and Justiniano et al. [2011] estimate the (inverse) Frisch's elasticity. We will estimate this parameter and analyze the effects caused by the difference in specifications in the later section.

A large number of "employment agencies" transform a bundle of specialized labor $N_{t}(j)$ into homogeneous labor inputs sold to intermediate-goods producers in a competitive market. Their transformation function is a constant elasticity of substitution (CES) form, $N_{t}=\left[\int_{0}^{1} N_{t}(j)^{1 /\left(\epsilon_{w, t}+1\right)} d j\right]^{\epsilon_{w, t}+1}$. Elasticity of substitution, $\epsilon_{w, t}$, follows the exogenous stochastic process. ${ }^{6}$

Profit maximization in a competitive market implies that the demand function for a specialized labor input $j$ is given by

$$
N_{t}(j)=\left[\frac{W_{t}(j)}{W_{t}}\right]^{-\left(1+\epsilon_{w, t}\right) / \epsilon_{w, t}} N_{t},
$$

where $W_{t}$ are real wages paid by intermediate-goods producers for homogeneous labor input and an aggregate index of wages for specialized labor.

As in Erceg, Henderson, and Levin [2000], a certain fraction, $\xi_{w} \in[0,1)$, of households cannot set their wages optimally at time $t$ and follow the wage indexation rule, $W_{t}(j)=$ $W_{t-1}(j)\left(\pi_{t-1}\right)^{\iota_{w}}(\bar{\pi})^{1-\iota_{w}} \bar{Z}$ where $\iota_{w} \in[0,1]$ is the degree of indexation to the past inflation, $\pi_{t-1} \equiv P_{t-1} / P_{t-2} . \quad \bar{\pi}$ and $\bar{Z}$ are steady-state inflation and economy-wide technological progress, respectively and subsequently explained.

The remaining households have an opportunity to reset their wages optimally to maximize (3) subject to the labor demand function (2),

$$
E_{t} \sum_{s=0}^{\infty} \xi_{w}^{s} \beta^{s}\left\{-v_{t+s}+\lambda_{t+s} W_{t}(j) \Pi_{k=1}^{s}\left(\pi_{t+k-1}\right)^{\iota_{w}}(\bar{\pi})^{1-\iota_{w}} \bar{Z}\right\} N_{t+s}(j),
$$

\footnotetext{
${ }^{6}$ As suggested in Chang and Schorfheide [2003], this shock is observationally equivalent to a labor supply shock. Hence, labor supply shocks in the household utility function are omitted to avoid the collision in identification.
} 
where $\lambda_{t}$ is the Lagrange multiplier on the households' flow of funds constraint.

\subsection{Final-goods producers}

Final-goods producers produce a final good $Y_{t}$ that combines a continuum of intermediate goods $\left\{Y_{t}(i)\right\}_{i \in[0,1]}$ and sell it in a competitive market. Their production function is a CES form, $Y_{t}=\left[\int_{0}^{1} Y_{t}(i)^{1 /\left(\epsilon_{p, t}+1\right)} d i\right]^{\epsilon_{p, t}+1}$. An elasticity of substitution, $\epsilon_{p, t}$, follows an exogenous stochastic process. Profit maximization in a competitive market implies that the demand function for an intermediate good $i$ is

$$
Y_{t}(i)=\left[\frac{P_{t}(i)}{P_{t}}\right]^{-\left(1+\epsilon_{p, t}\right) / \epsilon_{p, t}} Y_{t}
$$

where $P_{t}$ is an aggregate price index.

\subsection{Intermediate-goods producers}

Each intermediate-goods producer $i$ is a monopolistically competitive firm and indexed continuously within a unit interval. The producer is owned by households and produces an intermediate good $i$, according to the Cobb-Douglas production function of (5),

$$
Y_{t}(i)=\max \left\{A_{t}^{n}\left[L_{t-1}(i)^{\phi} K_{t-1}(i)^{1-\phi}\right]^{\alpha} N_{t}^{d}(i)^{1-\alpha}-Z_{t} F, 0\right\},
$$

where $L_{t}(i), K_{t}(i)$ and $N_{t}^{d}(i)$ represent quantities of land, capital, and labor employed by firm $i, F$ denotes a fixed cost of production, $A_{t}^{n}$ is an exogenous neutral technological progress, and $Z_{t}$ is an economy-wide technological progress that is a composite of neutral and investment-specific technologies. ${ }^{7}$

As in Calvo [1983], for every period, a certain fraction $\xi_{p} \in[0,1)$ of intermediategoods producers chosen randomly cannot set the price optimally. Instead, they set their prices according to the price indexation rule, $P_{t}(i)=P_{t-1}(i)\left(\pi_{t-1}\right)^{\iota_{p}}(\bar{\pi})^{1-\iota_{p}}$ where $\iota_{p} \in[0,1]$ is the degree of indexation to past inflation.

The remaining producers can reset prices to maximize the following discounted future profits subject to the demand function of (4),

$$
E_{t} \sum_{s=0}^{\infty} \xi_{p}^{s} \frac{\beta^{s} \Lambda_{t+s}}{\Lambda_{t}}\left\{\frac{P_{t}(i)}{P_{t+s}}\left[\Pi_{k=1}^{s}\left(\pi_{t+k-1}\right)^{\iota_{p}}(\bar{\pi})^{1-\iota_{p}}\right]-V_{t+s}\right\} Y_{t+s}(i),
$$

where $\Lambda_{t}$ is the marginal utility of households' consumption and $V_{t}$ is the real marginal cost. $^{8}$

\footnotetext{
${ }^{7}$ Given the production function in $(5), Z_{t}$ is defined as $Z_{t} \equiv\left(A_{t}^{n}\right)^{1 /[1-(1-\phi) \alpha]}\left(A_{t}^{i}\right)^{(1-\phi) \alpha /[1-(1-\phi) \alpha]}$.

${ }^{8} \mathrm{An}$ intermediate-goods producer solves a cost-minimization problem, taking input prices as given, regardless of whether the producer can adjust its price optimally. The solution yields the marginal cost function, $V_{t}=(\alpha \phi)^{-\alpha \phi}(\alpha(1-\phi))^{-\alpha(1-\phi)}(1-\alpha)^{1-\alpha}\left[\left(W_{t}\right)^{1-\alpha}\left(r_{t}^{k}\right)^{\alpha(1-\phi)}\left(r_{t}^{l}\right)^{\alpha \phi}\right] / Z_{t}$.
} 


\subsection{Government}

As in Smets and Wouters [2007], a monetary authority follows a generalized Taylor rule that gradually adjusts the nominal interest rate in response to inflation and output deviations from its hypothetical counterpart under the flexible price economy,

$$
\frac{R_{t}}{\bar{R}}=\left(\frac{R_{t-1}}{\bar{R}}\right)^{\rho_{r}}\left[\left(\frac{\pi_{t}}{\bar{\pi}}\right)^{\phi_{\bar{\pi}}}\left(\frac{Y_{t}}{Y_{t}^{*}}\right)^{\phi_{y}}\right]^{1-\rho_{r}}\left[\frac{Y_{t} / Y_{t-1}}{Y_{t}^{*} / Y_{t-1}^{*}}\right]^{\phi_{d y}} m p_{t},
$$

where $m p_{t}$ is an exogenous monetary policy shock.

Government spending is a fraction of output, however its share is exogenously varying.

$$
G_{t}=\left(1-\frac{1}{g_{t}}\right) Y_{t}
$$

where $g_{t}$ is an exogenous government spending shock.

\subsection{Process of exogenous shocks}

We assume three types of exogenous-shock processes in this economy. The first type is specified in (6): a logarithm of shock $x$ follows an autoregressive of order one (AR(1)) process around its steady-state value $\bar{x}$. MEI, collateral constraint, housing demand, patience, monetary policy, and government expenditure shocks belong to this family. The second type is specified in (7): the growth rates of neutral and investment-specific technology shocks follow an AR(1) process around deterministic growth rates. The third type is specified in (8). As is commonly adopted in DSGE empirical studies, price and wage markup shocks in the logarithm follow an autoregressive of order one with a first-order moving average $(\operatorname{ARMA}(1,1))$ process around their steady-state values. ${ }^{9}$ The ARMA process is suitable to capture the volatile fluctuations in price and wage inflations.

$$
\begin{aligned}
\log \left(x_{t}\right) & =\left(1-\rho_{x}\right) \log (\bar{x})+\rho_{x} \log \left(x_{t-1}\right)+\eta_{x, t}, \quad x \in\{\zeta, \theta, \varphi, v, m p, g\}, \\
\Delta \log \left(A_{t}^{x}\right) & =\left(1-\rho_{x}\right) \Delta \log \left(\bar{A}^{x}\right)+\rho_{x} \Delta \log \left(A_{t-1}^{x}\right)+\eta_{x, t}, \quad x \in\{n, i\}, \\
\log \left(\epsilon_{x, t}\right) & =\left(1-\rho_{x}\right) \log \left(\bar{\epsilon}_{x}\right)+\rho_{x} \log \left(\epsilon_{x, t-1}\right)+\eta_{x, t}-\theta_{x} \eta_{x, t-1}, \quad x \in\{p, w\} .
\end{aligned}
$$

\footnotetext{
${ }^{9}$ Following conventions in the literature (e.g., Smets and Wouters [2007]), we normalize the price and wage markup shock to be a unit coefficient in the linearized price and wage Eular equations, respectively.
} 


\subsection{Market clearing}

All markets clear in equilibrium. Market clearing conditions for goods, labor, land, and bonds are denoted as follows:

$$
\begin{aligned}
Y_{t} & =C_{t}+I_{t} / A_{t}^{i}+G_{t}, \\
N_{t} & =N_{t}^{d}, \\
\bar{L} & =L_{h, t}+L_{c, t}, \\
B_{t} & =B_{t}^{d}
\end{aligned}
$$

where $\bar{L}$ is the total supply of land.

Because levels of neutral and investment-specific technologies introduce non-stationarities into the model, we render variables stationary by detrending their respective stochastic trends. Equilibrium conditions are then log-linearized. Finally, the linearized system of rational expectations is solved into state-space representation and estimated.

\section{Estimation method and data}

We employ Bayesian methods to estimate posterior distributions of the model's structural parameters. ${ }^{10}$ The likelihood function and priors are incorporated using the Bayes formula, and the resulting conditional distributions of parameters are posterior distributions.

Table 1: Parameter calibration

\begin{tabular}{llc}
\hline \hline Parameters & Description & Calibrated values \\
\hline$\beta$ & Households' discount factor & 0.9925 \\
$\hat{\beta}$ & Capital owners' discount factor & 0.97 \\
$1-\alpha$ & Labor share & 0.65 \\
$\bar{\theta}$ & LTV ratio & 0.75 \\
$\left(\epsilon_{p}-1\right) / \epsilon_{p}$ & Steady state price markup & 0.85 \\
$\left(\epsilon_{w}-1\right) / \epsilon_{w}$ & Steady state wage markup & 0.85 \\
$\bar{q}_{l} \bar{L}_{h} / \bar{Y}$ & Households' landholdings over GDP at annual frequency & 1.45 \\
$\bar{q}_{l} \bar{L}_{e} / \bar{Y}$ & Capital owners' landholdings over GDP at annual frequency & 0.65 \\
$\bar{G} / \bar{Y}$ & Government expenditure to GDP & 0.22 \\
$\bar{I} / \bar{K}$ & Investment over Capital & 0.21 \\
$\bar{K} / \bar{Y}$ & Capital to GDP at annual frequency & 1.15 \\
\hline \hline
\end{tabular}

We calibrate some parameters to values that are conventional in the literature. Specifically, households' discount factor is 0.9925 , which is equivalent to a 1 percent discount rate per annum. Capital owners' discount factor is 0.97. This value is used in Iacoviello and Neri [2010]. ${ }^{11}$ The share parameter of labor in production is 0.65 . We set the steadystate LTV ratio $\bar{\theta}$ as 0.75 to be consistent with Liu et al. [2013]. Given this calibration, the credit to GDP ratio $(B / Y)$ at the steady state can be approximated to the historical

\footnotetext{
${ }^{10} \mathrm{An}$ and Schorfheide [2007] provide a survey of Bayesian estimation of DSGE models.

${ }^{11}$ We re-estimated the model with alternative calibration $(\hat{\beta}=0.985)$ and found that results are almost similar to those with the baseline calibration.
} 
average at annual frequency. The average markup ratios of price and wage are 15 percent. Land-holdings to GDP of households and capital owners are equivalent to those of Liu et al. [2013]. The other values are selected to be consistent with historical averages. Some parameters are implicitly calculated from the steady state relationships. For example, the relative factor share of land to capital in the production function $\phi$ is calculated as $\phi=\frac{\bar{q}_{\bar{L}} / \bar{L}_{e}}{\hat{\beta} \alpha\left(\epsilon_{p}-1\right) / \epsilon_{p}}=0.124$.

Most prior distributions of parameters in Table 2 are in line with those in previous studies. The prior of persistent parameters is a Beta distribution with mean 0.6 and standard deviation 0.15 . The only exception is monetary policy shocks. We assign a less persistent prior mean, 0.2 , to clearly identify between the policy-rule's inertia and the persistence of discretionary policy shocks. Priors on the standard deviation of innovations are quite diffuse.

The model is estimated using 10 U.S. quarterly time series data items: logarithmic first differences of private consumption, private business investments, land prices, credits, the inverse of the relative price of investment goods, real wages, and GDP, the number of labor hours, the nominal inflation of the consumption deflator, and the nominal effective federal funds rate. We remove the sample means from all data to focus on the dynamics at business cycle frequencies, as in Christiano, Motto, and Rostagno [2014].

The details of the datasets are as follows. Consumption is personal consumption expenditures on non-durables and services. Investments represent the sum of personal consumption expenditures on durables and gross private domestic investments, including inventory investments. Labor input is the log of total hours per person in the non-farm business sector. Credit is debt of non-financial corporations. Land price is the FHFA based liquidity-adjusted price index for residential land and is developed by Davis and Heathcote [2007] and updated by Morris A. Davis. Following Justiniano et al. [2011], the consumption deflator is a chain-weighted price index of personal consumption expenditures on non-durables and services. The relative price of an investment is a chain-weighted price index of the previously described investments divided by the consumption deflator. Consumption, investments, credits, GDP, real wages, and land prices are deflated by the consumption deflator and, except for land prices, divided by the number of persons older than age 16 years in the population. The sample covers 1975/1Q to 2009/1Q. To make our results comparable to Justiniano et al. [2011] and avoid the effects of a zero bound on nominal interest rates, the end of the sample is 2009/1Q. ${ }^{12}$

Our model and dataset encompass those of Liu et al. [2013] and Justiniano et al. [2011]. Specifically, we add price and wage inflations, policy rate, and GDP to the dataset of Liu et al. [2013], who estimate a flexible-price RBC model with collateral constraints. We add land prices and credits to the dataset of Justiniano et al. [2011], who estimate a standard medium-scale DSGE model with price and wage stickiness but without collateral constraints.

For the posterior distribution, we create two chains of 200,000 draws using the MetropolisHastings algorithm, and discarded the first 50 percent of these draws. The acceptance

\footnotetext{
${ }^{12}$ Hirose and Inoue [2016] point out that the zero lower bound on nominal interest rates causes biased estimates of structural shocks even if estimated parameters are virtually unbiased. The results are almost unchanged even if the end of the sample is 2008/4Q.
} 
ratios of the Markov Chain Monte Carlo simulation are 37.82 and 37.63 percent in the respective chains. The multivariate and univariate diagnostics of Brooks and Gelman [1998] suggest that the estimation has converged.

\section{Estimation results}

Table 2 presents the posteriors of the parameters. Tight credible intervals suggest that the parameters are firmly estimated. ${ }^{13}$

Posterior parameters are within variations in previous DSGE estimations. The inverse Frisch elasticity (4.056), which is assumed to be zero in Liu et al. [2013], is statistically significant and similar to that of Justiniano et al. [2011] (4.444). One of the controversial parameters is the investment adjustment cost. Ours (0.552) is in the midrange of these studies: 0.175 for Liu et al. [2013], 2.657 for Justiniano et al. [2011], and 5.74 for Smets and Wouters [2007]. Regarding the other major parameters, consumption habit persistence is 0.775 for households and 0.477 for capital owners. Both are similar to values in previous studies such as Smets and Wouters [2007] (0.71) and Liu et al. [2013] (0.5000.658). They are slightly lower than the value in Justiniano et al. [2011] (0.859). Price and wage reset probabilities and the degrees of indexation resemble those in Justiniano et al. [2011], although these nominal parameters are not estimated in Liu et al. [2013].

To ensure the identification between housing demand and investment shocks, we check the correlations between the draws from marginal posterior distributions of related parameters. One is the standard deviations of the housing demand and investment shocks and the other is the autoregressive parameters of these shocks. Further, we execute the same exercise with respect to the LTV and investment shocks. Table 3 suggests that investment shocks and housing demand (and LTV) shocks are clearly identified, showing that all the correlation coefficients are small and less than or equal to $10 \%$.

Next, we evaluate the cyclical properties of the model and data. Business cycles are fluctuations of aggregate economic activities occurring at approximately the same time in many variables. Figure 1 displays cross correlations between output and other variables to examine whether the model is successful in capturing business cycle co-movements. The shaded areas are the 95 percent confidence intervals of empirical cross correlations and the solid lines are theoretical cross correlations of the baseline model. The figure shows that our model can generate procyclical co-movements among important variables. In particular, the figure well captures the cross correlation of investments, which is our primary focus. The figure also indicates that there still remains a further room for improvements in terms of the empirical fit. An introduction of adjustment costs in land transactions and financial contracts may help to improve the cross correlations of land prices and credits.

\footnotetext{
${ }^{13}$ We check the estimated Lagrange multiplier on collateral constraint. It is fluctuating but is significantly away from zero. As suggested in Jermann and Quadrini [2012], this result implies the collateral constraint was binding during the period.
} 
Table 2: Prior and posterior distributions of parameters

\begin{tabular}{|c|c|c|c|c|c|c|c|}
\hline \multirow{3}{*}{\multicolumn{2}{|c|}{ Panel I: structural parameters }} & \multicolumn{3}{|c|}{ Prior } & \multicolumn{3}{|c|}{ Posterior } \\
\hline & & \multirow{2}{*}{ Distribution } & \multirow[t]{2}{*}{ Mean } & \multirow[t]{2}{*}{ S.D. } & \multirow[t]{2}{*}{ Mean } & \multicolumn{2}{|c|}{$95 \%$ interval } \\
\hline & & & & & & & \\
\hline$\gamma_{l}$ & Habit formation $(\mathrm{HH})$ & B & 0.60 & 0.15 & 0.775 & 0.721 & 0.828 \\
\hline$\gamma_{b}$ & Habit formation (C) & B & 0.60 & 0.15 & 0.477 & 0.302 & 0.650 \\
\hline$\xi_{p}$ & Calvo (price) & B & 0.60 & 0.15 & 0.810 & 0.741 & 0.882 \\
\hline$\xi_{w}$ & Calvo (wage) & B & 0.60 & 0.15 & 0.805 & 0.674 & 0.936 \\
\hline$\iota_{p}$ & Price indexation & B & 0.60 & 0.15 & 0.195 & 0.080 & 0.307 \\
\hline$\iota_{w}$ & Wage indexation & B & 0.60 & 0.15 & 0.256 & 0.149 & 0.365 \\
\hline$\Omega$ & Investment adjustment cost & $\Gamma$ & 5.00 & 3.00 & 0.552 & 0.316 & 0.775 \\
\hline$\chi$ & Inverse Frisch elasticity & $\Gamma$ & 2.00 & 0.75 & 4.056 & 2.670 & 5.383 \\
\hline$F / \bar{Y}$ & Fixed cost per output & B & 0.15 & 0.05 & 0.088 & 0.045 & 0.127 \\
\hline$\phi_{\pi}$ & Policy rule (inflation) & $\Gamma$ & 1.50 & 0.15 & 1.411 & 1.203 & 1.624 \\
\hline$\phi_{y}$ & Policy rule (output) & $\boldsymbol{\Gamma}$ & 0.20 & 0.10 & 0.073 & 0.043 & 0.102 \\
\hline$\phi_{d y}$ & Policy rule (output growth) & $\boldsymbol{\Gamma}$ & 0.20 & 0.10 & 0.466 & 0.363 & 0.568 \\
\hline$\rho_{r}$ & Policy rule (policy inertia) & B & 0.60 & 0.15 & 0.768 & 0.707 & 0.827 \\
\hline \multicolumn{8}{|c|}{ Panel II: autocorrelations and moving-averages of shocks } \\
\hline$\rho_{v}$ & Preference & B & 0.60 & 0.15 & 0.621 & 0.502 & 0.746 \\
\hline$\rho_{n}$ & Neutral technology & B & 0.60 & 0.15 & 0.288 & 0.201 & 0.375 \\
\hline$\rho_{i}$ & Investment-specific technology & B & 0.60 & 0.15 & 0.249 & 0.159 & 0.332 \\
\hline$\rho_{\phi}$ & Housing demand & B & 0.60 & 0.15 & 0.995 & 0.991 & 0.998 \\
\hline$\rho_{\theta}$ & LTV & B & 0.60 & 0.15 & 0.969 & 0.958 & 0.981 \\
\hline$\rho_{\zeta}$ & MEI & B & 0.60 & 0.15 & 0.721 & 0.658 & 0.780 \\
\hline$\rho_{p}$ & Price markup & B & 0.60 & 0.15 & 0.917 & 0.873 & 0.966 \\
\hline$\theta_{p}$ & Price markup (MA) & B & 0.50 & 0.15 & 0.727 & 0.598 & 0.865 \\
\hline$\rho_{w}$ & Wage markup & B & 0.60 & 0.15 & 0.804 & 0.610 & 0.976 \\
\hline$\theta_{w}$ & Wage markup (MA) & B & 0.50 & 0.15 & 0.760 & 0.551 & 0.960 \\
\hline$\rho_{m p}$ & Monetary policy & B & 0.20 & 0.05 & 0.210 & 0.132 & 0.287 \\
\hline$\rho_{g}$ & Government & B & 0.60 & 0.15 & 0.909 & 0.878 & 0.940 \\
\hline \multicolumn{8}{|c|}{ Panel III: standard deviations of shocks } \\
\hline$\sigma_{v}$ & Preference & $\boldsymbol{\Gamma}^{-1}$ & 0.50 & 1.00 & 2.141 & 1.696 & 2.595 \\
\hline$\sigma_{n}$ & Neutral technology & $\boldsymbol{\Gamma}^{-1}$ & 0.10 & 1.00 & 0.657 & 0.589 & 0.724 \\
\hline$\sigma_{i}$ & Investment-specific technology & $\boldsymbol{\Gamma}^{-1}$ & 0.10 & 1.00 & 0.547 & 0.494 & 0.601 \\
\hline$\sigma_{\phi}$ & Housing demand & $\boldsymbol{\Gamma}^{-1}$ & 0.50 & 1.00 & 6.737 & 4.650 & 8.655 \\
\hline$\sigma_{\theta}$ & LTV & $\boldsymbol{\Gamma}^{-1}$ & 0.50 & 1.00 & 1.474 & 1.320 & 1.626 \\
\hline$\sigma_{\zeta}$ & MEI & $\boldsymbol{\Gamma}^{-1}$ & 0.50 & 1.00 & 2.201 & 1.774 & 2.606 \\
\hline$\sigma_{p}$ & Price markup & $\boldsymbol{\Gamma}^{-1}$ & 0.50 & 1.00 & 0.259 & 0.215 & 0.302 \\
\hline$\sigma_{w}$ & Wage markup & $\boldsymbol{\Gamma}^{-1}$ & 0.10 & 1.00 & 0.352 & 0.297 & 0.405 \\
\hline$\sigma_{m p}$ & Monetary policy & $\boldsymbol{\Gamma}^{-1}$ & 0.10 & 1.00 & 0.338 & 0.281 & 0.394 \\
\hline & Government & $\boldsymbol{\Gamma}^{-1}$ & 0.50 & 1.00 & 1.601 & 1.440 & 1.766 \\
\hline & Log marginal likelihood & & & & & \multicolumn{2}{|c|}{-1847.235} \\
\hline
\end{tabular}

Note: Habit formation $(\mathrm{HH})$ and Habit formation(C) represent the degree of consumption habit formation of households and capital owners, respectively. MA represents a moving-average parameter. $\mathbf{B}, \boldsymbol{\Gamma}$, and $\boldsymbol{\Gamma}^{-1}$ correspond to the beta, gamma, and inversed gamma distributions. 
Table 3: Identification between the investment and collateral-related shocks

\begin{tabular}{cccc}
\hline \multicolumn{2}{c}{ Investment versus housing demand shocks } & \multicolumn{2}{c}{ Investment versus LTV shocks } \\
S.D. & AR(1) & S.D. & AR(1) \\
\hline 0.043 & -0.016 & 0.103 & -0.034 \\
\hline \hline
\end{tabular}

Note: Table shows the correlation coefficients between the draws from marginal posterior distributions.

Figure 1: Cyclicalities of selected variables: data and model
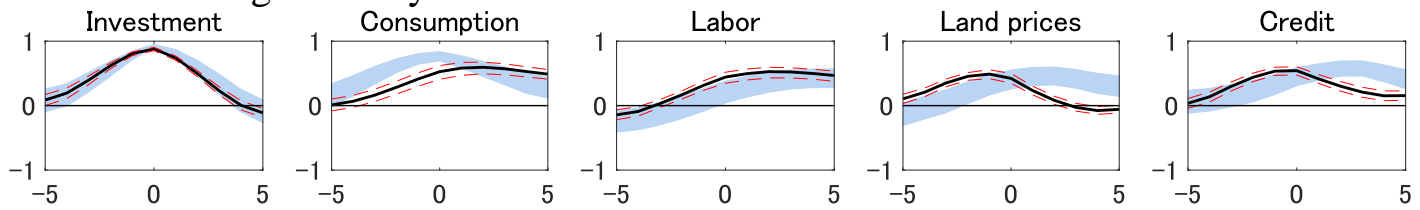

Note: Figure 1 displays cross correlations of selected variables with contemporaneous GDP. The solid and dotted lines represent the cross correlations calculated from the baseline model and 95 percent credible intervals, respectively. The shaded areas are the 95 percent intervals of the correlation coefficients of the data. All data are transformed into year-on-year growth rates.

\subsection{Which shock is important at business cycle frequencies?}

This subsection addresses our main question: what is the major source of business cycle fluctuations? Table 4 presents the contribution of each shock to the variance of the variables at business cycle frequencies. Following Stock and Watson [1999], we define business cycles as cycles between 6 and 32 quarters. ${ }^{14}$

First of all, Table 4 reports that housing demand shocks account for 74.9 percent of land-price fluctuations. Housing demand shocks determine most of land-price fluctuations. Second, Table 4 suggests that neither housing demand shocks nor investment shocks are the major determinant of business cycle fluctuations, ${ }^{15}$ indicating that the primary driver of business cycles is the technology shocks that account for 44.9 percent of output fluctuations. Housing demand shocks account for 14.8 percent of output fluctuations and 23.0 percent of investment fluctuations. These results are different from those reported in Liu et al. [2013], in which 28.32 and 38.31 percent of output and investment variations, respectively, are attributed to housing demand shocks. ${ }^{16}$ Furthermore, MEI shocks play a minor role in business cycles. They account for only 2.6 percent of fluctuations in output and 6.7 percent of fluctuations in investments.

\footnotetext{
${ }^{14} \mathrm{We}$ split the whole sample period into the first and second half, and re-estimate the model in these subsamples. Specifically, the first and second half of sample periods covers 1975/1Q to 1992/4Q and 1993/1Q to 2009/1Q, respectively. Our results are robust to these subsample estimations. See the online appendix for the detail.

${ }^{15}$ To check whether our results have an issue of weak identification, we compare prior and posterior densities of the share of variance in variables due to housing demand shocks and confirm that posterior density differs from prior density, indicating the likelihood information is used for the posterior variance decomposition.

${ }^{16}$ Since Liu et al. [2013] provide variance decompositions only in time domain, we pick these numbers from the results of variance decompositions at eight quarters.
} 
Table 4: Variance decomposition at business cycle frequencies: baseline case

\begin{tabular}{|c|c|c|c|c|c|c|c|c|c|c|}
\hline & \multirow{3}{*}{$\begin{array}{l}\text { Housing } \\
\text { demand }\end{array}$} & \multirow{3}{*}{ LTV } & \multirow{3}{*}{ MEI } & \multicolumn{4}{|c|}{ Supply } & \multicolumn{3}{|c|}{ Other demand } \\
\hline & & & & \multicolumn{2}{|c|}{ Technologies } & \multicolumn{2}{|c|}{ Markups } & \multirow{2}{*}{$\begin{array}{l}\text { Pati- } \\
\text { ence }\end{array}$} & \multirow{2}{*}{$\begin{array}{c}\text { Monetary } \\
\text { policy }\end{array}$} & \multirow[t]{2}{*}{ Gov't } \\
\hline & & & & Neutral & IS & Price & Wage & & & \\
\hline \multirow[t]{2}{*}{$Y_{o b s}$} & 14.8 & 13.9 & 2.6 & 43.8 & 1.1 & 2.9 & 1.3 & 1.3 & 16.6 & 0.3 \\
\hline & {$[11.2,19.3]$} & {$[10.2,18.5]$} & {$[1.4,4.6]$} & {$[35.4,53.4]$} & {$[0.7,1.7]$} & {$[1.4,5.4]$} & {$[0.6,2.8]$} & {$[0.7,2.1]$} & {$[12.2,22.4]$} & {$[0.2,0.5]$} \\
\hline \multirow[t]{2}{*}{$I_{o b s}$} & 23.0 & 18.8 & 6.7 & 17.2 & 1.0 & 3.7 & 1.0 & 7.9 & 17.0 & 2.3 \\
\hline & {$[18.5,28.2]$} & {$[14.8,23.7]$} & {$[4.3,9.8]$} & {$[12.9,22.7]$} & {$[0.6,1.5]$} & {$[2.1,6.4]$} & {$[0.4,2.2]$} & {$[5.2,11.8]$} & {$[12.9,22.1]$} & {$[1.5,3.5]$} \\
\hline \multirow[t]{2}{*}{$C_{o b s}$} & 5.9 & 9.4 & 4.7 & 41.0 & 3.3 & 1.3 & 2.4 & 13.0 & 13.3 & 3.6 \\
\hline & {$[3.7,8.4]$} & {$[6.5,12.8]$} & {$[2.5,7.8]$} & {$[32.8,50.2]$} & {$[2.3,4.8]$} & {$[0.6,2.7]$} & {$[0.8,5.7]$} & {$[8.2,19.5]$} & {$[7.9,20.9]$} & {$[2.2,5.7]$} \\
\hline \multirow[t]{2}{*}{$N_{o b s}$} & 13.2 & 6.5 & 17.1 & 10.8 & 0.4 & 11.8 & 7.4 & 0.4 & 29.5 & 0.4 \\
\hline & {$[9.1,18.1]$} & {$[3.2,10.7]$} & {$[11.7,24.1]$} & {$[7.2,15.4]$} & {$[0.2,0.8]$} & {$[7.0,18.9]$} & {$[4.0,13.4]$} & {$[0.1,1.0]$} & {$[21.0,41.7]$} & {$[0.2,0.6]$} \\
\hline \multirow[t]{2}{*}{$Q_{l, o b s}$} & 74.9 & 3.2 & 2.9 & 9.3 & 1.2 & 0.3 & 0.7 & 2.0 & 3.6 & 1.2 \\
\hline & {$[69.6,79.8]$} & {$[2.3,4.5]$} & {$[1.9,4.3]$} & {$[6.7,12.9]$} & {$[0.8,1.8]$} & {$[0.1,0.7]$} & {$[0.3,1.6]$} & {$[1.1,3.5]$} & {$[2.0,5.6]$} & {$[0.8,1.8]$} \\
\hline \multirow[t]{2}{*}{$B_{o b s}$} & 25.5 & 47.0 & 10.7 & 2.6 & 3.9 & 1.1 & 0.5 & 2.2 & 5.1 & 0.7 \\
\hline & {$[21.0,30.9]$} & [41.1.,53.3] & {$[7.7,14.8]$} & {$[1.8,3.6]$} & {$[2.9,5.4]$} & {$[0.4,2.2]$} & {$[0.2,0.8]$} & {$[1.4,3.2]$} & {$[3.8,6.9]$} & {$[0.5,1.0]$} \\
\hline
\end{tabular}

Note: Variance decomposition to periodic components with cycles between 6 and 32 quarters is presented using the spectrum of the linearized model. The spectrum density is computed from the state space representation of the model with 3,000 bins for frequency covering that range of periodicities. To reconstruct the levels of output, investments, consumption, and land prices, we apply an inverse first difference filter. 95 percent credible intervals are denoted in respective parenthesis under the mean estimates.

\subsection{Why are housing demand shocks not important?}

Compared with the empirical exercises in Liu et al. [2013] that claims housing demand shocks are the primary driving force of business cycles, our model is different in two respects. One is the nominal rigidities and the other is the finite labor supply elasticity. The latter is key to our conclusion.

To analyze the role of these differences in specifications, Table 5 presents variance decompositions in hypothetical economies with an infinite labor supply elasticity and without nominal rigidities. The infinite Frisch elasticity rows show that spillovers from housing demand becomes a major source of business cycles when the Frisch elasticity of labor supply is calibrated at infinite as in Liu et al. [2013]. Specifically, housing demand shocks can account for 28.2 percent of output variations and 30.5 percent of investment variations. The contributions of housing demand shocks approach to the results reported in Liu et al. [2013]: 28.3 percent for output variations and 38.7 percent for investment variations. In contrast, the drop nominal frictions rows report that the contributions of housing demand shocks are similar to those in the baseline case even when nominal price and wage stickinesses are almost muted. ${ }^{17}$ These decompositions clearly indicate that shifting housing demand matters for business cycles only when the labor supply elasticity is infinitely high.

The higher Frisch elasticity leads to the greater substitution effects. A positive housing

\footnotetext{
${ }^{17}$ Specifically, we set Calvo parameters of price and wage changes are 0.9 and indexation parameters of price and wage are 0.0, as in the similar exercises of Smets and Wouters [2007].
} 
Table 5: Variance decomposition at business cycle frequencies: hypothetical cases I

\begin{tabular}{llcccccc}
\hline \hline \multirow{2}{*}{$Y_{\text {obs }}$} & $\begin{array}{c}\text { Housing } \\
\text { demand }\end{array}$ & LTV & MEI & $\begin{array}{c}\text { Tech- } \\
\text { nologies }\end{array}$ & $\begin{array}{c}\text { Mark- } \\
\text { ups }\end{array}$ & $\begin{array}{c}\text { Other } \\
\text { demands }\end{array}$ \\
& infinite Frisch elasticity & 28.2 & 15.8 & 4.9 & 23.8 & 1.9 & 24.2 \\
& drop nominal frictions & 14.5 & 15.4 & 0.1 & 59.1 & 0.0 & 10.2 \\
\multirow{2}{*}{$I_{\text {obs }}$} & & & & & & \\
& baselinecase & 23.0 & 18.8 & 6.7 & 18.1 & 4.7 & 27.2 \\
& infinite Frisch elasticity & 30.5 & 17.6 & 7.9 & 9.4 & 1.3 & 32.3 \\
& drop nominal frictions & 24.9 & 22.0 & 1.9 & 23.9 & 0.0 & 25.8 \\
& & & & & & & \\
$C_{\text {obs }}$ & baseline case & 5.9 & 9.4 & 4.7 & 44.3 & 3.7 & 29.8 \\
& infinite Frisch elasticity & 17.0 & 10.0 & 2.9 & 43.4 & 3.4 & 21.8 \\
& drop nominal frictions & 5.1 & 9.1 & 5.4 & 47.9 & 0.0 & 31.4 \\
& & & & & & & \\
$Q_{l, o b s}$ & baseline case & 74.9 & 3.2 & 2.9 & 10.5 & 1.0 & 6.7 \\
& infinite Frisch elasticity & 76.3 & 3.3 & 1.2 & 8.6 & 0.7 & 9.4 \\
& drop nominal frictions & 78.3 & 2.4 & 5.6 & 8.2 & 0.0 & 4.8 \\
& & & & & & & \\
$B_{\text {obs }} \quad$ baseline case & 25.5 & 47.0 & 10.7 & 6.5 & 1.5 & 7.9 \\
& infinite Frisch elasticity & 32.6 & 41.7 & 2.9 & 5.0 & 0.9 & 16.0 \\
& drop nominal frictions & 14.5 & 15.4 & 0.1 & 59.1 & 0.0 & 10.2 \\
\hline \hline
\end{tabular}

Note: "Other demands", "Technologies", and "Markups" correspond to the contributions of "patience", "monetary policy", and "government expenditure" shocks, those of "neutral" and "investment-specific" technology shocks, and those of "price" and "wage" markup shocks, respectively. For computational details, see also the Note for Table 4. In the infinite Frisch elasticity case, the model and parameters are same as the baseline case except for inverse Frisch elasticity $\chi=0$. In the drop nominal frictions case, the model and the parameters are the same as the baseline case except for the four parameters $\left\{\xi_{x}, \iota_{x}\right\}$ for $x=p, w$. The Calvo probabilities for price and wage changes are calibrated at 0.90 and the price and wage indexations are calibrated at 0.0 . 
demand shock, which increases the land prices and available funds by relaxing the collateral constraint, will strengthen the amplification effect of the shock. In contrast, the lower Frisch elasticity, which is consistent with micro evidence and estimated medium-scale DSGE models, leads to the greater income effects. In this case, a shock amplification upon a positive housing demand shock is limited even if rising collateral values increases available funds through the relaxation of collateral constraint.

Figure 2: Impulse responses to a housing demand shock and an MEI shock
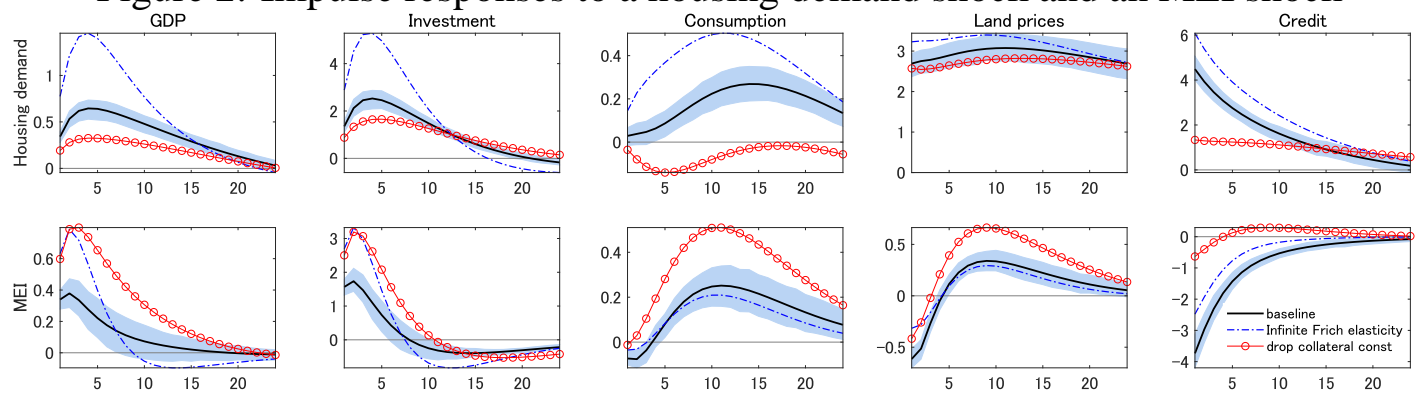

Note:The upper and lower panels are impulse responses to one standard deviation of housing demand and MEI shocks, respectively. The solid lines are the medians, whereas the shaded areas represent the 95th percentile intervals in the baseline model. The broken lines and marker lines are responses in hypothetical economy without nominal frictions and collateral constraints, respectively.

The upper panels of Figure 2 assist in understanding this point, by displaying the impulse responses of selected variables to a positive housing demand shock. Thick and broken lines correspond to the baseline and infinite Frisch elasticity cases, respectively. They show that output, investments, and consumption move in tandem in a hump-shared pattern. Land prices and credits also co-move procyclically. However, the amplification effects of housing demand shocks are greater in the infinite Frisch elasticity case. The peak responses of output and investments are approximately three times greater that those in the baseline case. These responses are reflections of amplification effects of the higher Frisch elasticity.

\subsection{Why are investment shocks not important?}

Compared with the empirical exercises in Justiniano et al. [2011] that claim MEI shocks are the primary driving force of business cycles, we impose a collateral constraint on capital owners' funding and add land prices and credits to the dataset for estimation.

To understand the roles of collateral constraint, the lower panels of Figure 2 presents the impulse responses of variables to an MEI shock. An MEI shock cannot reproduce the procyclical responses of land prices and credits in the data shown in Figure 1 although this shock successfully generates co-movements in output, investments, and consumption. In particular, the response of credits is completely opposite for entire simulation periods.

Contrasting credits' responses are due to the combination of collateral constraints and stock price responses. MEI shocks are supply shocks that shift the marginal cost curve for building capital. For this reason, an MEI shock lowers stock prices, which is the price of capital, while it has an expansionary impact on production, investments, and consumption. 
Table 6: Variance decomposition at business cycle frequencies: hypothetical cases II

\begin{tabular}{llcccccc}
\hline \hline & & $\begin{array}{c}\text { Housing } \\
\text { demand }\end{array}$ & LTV & MEI & $\begin{array}{c}\text { Tech- } \\
\text { nologies }\end{array}$ & $\begin{array}{c}\text { Mark- } \\
\text { ups }\end{array}$ & $\begin{array}{c}\text { Other } \\
\text { demands }\end{array}$ \\
\hline$Y_{\text {obs }}$ & baseline case & 14.8 & 13.9 & 2.6 & 44.8 & 4.1 & 18.2 \\
& drop collateral const. & 5.7 & 0.0 & 22.7 & 42.4 & 10.1 & 17.1 \\
& drop collateral const. and $B_{\text {obs }} \mathcal{E} Q_{l, o b s}$ & 0.0 & 0.0 & 44.7 & 37.4 & 9.7 & 6.4 \\
& & & & & & \\
$I_{\text {obs }}$ & baselinecase & 23.0 & 18.8 & 6.7 & 18.1 & 4.7 & 27.2 \\
& drop collateral const. & 14.8 & 0.0 & 39.4 & 15.3 & 11.1 & 17.7 \\
& drop collateral const. and $B_{\text {obs }} \mathcal{E} Q_{l, o b s}$ & 0.0 & 0.0 & 73.6 & 11.8 & 7.1 & 6.2 \\
& & & & & & \\
$C_{\text {obs }}$ & baseline case & 5.9 & 9.4 & 4.7 & 44.3 & 3.7 & 29.8 \\
& drop collateral const. & 2.1 & 0.0 & 20.2 & 39.5 & 7.8 & 27.7 \\
& drop collateral const. and $B_{\text {obs }} \mathcal{E} Q_{l, o b s}$ & 0.0 & 0.0 & 32.8 & 30.9 & 9.5 & 24.0 \\
$Q_{l, o b s}$ & & & & & & \\
& baseline case & 74.9 & 3.2 & 2.9 & 10.5 & 1.0 & 6.7 \\
& drop collateral const. & 71.7 & 0.0 & 7.6 & 10.4 & 2.1 & 7.3 \\
& drop collateral const. and $B_{o b s} \mathcal{E} Q_{l, o b s}$ & 0.0 & 0.0 & 36.1 & 29.4 & 9.8 & 21.1 \\
& & & & & & & \\
$B_{\text {obs }}$ & baseline case & 25.5 & 47.0 & 10.7 & 6.5 & 1.5 & 7.9 \\
& drop collateral const. & 39.8 & 39.9 & 5.3 & 7.5 & 2.3 & 4.4 \\
drop collateral const. and $B_{\text {obs }} \mathcal{E} Q_{l, o b s}$ & 0.0 & 1.2 & 46.5 & 22.7 & 7.2 & 16.8 \\
\hline \hline
\end{tabular}

Note: "Other demands", "Technologies", and "Markups" correspond to the contributions of "patience", "monetary policy", and "government expenditure" shocks, those of "neutral" and "investment-specific" technology shocks, and those of "price" and "wage" markup shocks, respectively. For computational details, see also the Note for Table 4 . In the without collateral const. case, the model and the parameters are the same as the baseline case except for $\bar{\theta}=0.001$. In the without collateral const. and $B_{o b s} \mathcal{E} Q_{i, o b s}$ case, the baseline model is evaluated at the posterior mean of parameters re-estimated with calibrated at $\bar{\theta}=0.001$ and without using credits and land prices data. 
Justiniano et al. [2011] admit this decline in stock prices during a boom as a shortcoming of an MEI shock. Stock price movements are translated into credit responses through the collateral constraint. The marked line in the lower panel of Figure 2 illustrates the negative response of credits almost disappears once the collateral constraint is dropped.

Table 6 presents variance decompositions in a hypothetical economy without collateral constraints. The drop collateral constraints rows show that spillovers from collateralrelated shocks (i.e. housing demand and LTV shocks) become smaller than those in the baseline case and MEI shocks become an important driver of business cycles instead. Specifically, MEI shocks account for 22.7 percent of output variations and 39.4 percent of investment variations, whereas housing demand shocks account for 5.7 percent of output variations and 14.8 percent of investment variations.

In addition, we re-estimate the model without collateral constraint and with dropping land prices and credits data. ${ }^{18}$ This alternative formulation is similar to that of Justiniano et al. [2011]. The drop collateral const. and $B_{o b s} \mathcal{E} Q_{l, o b s}$ rows in Table 6 report that MEI shocks account for 44.7 and 73.6 percent of output and investment variations. The contribution of MEI shocks increases and approximates to the results reported in Justiniano et al. [2011].

\section{Conclusion}

Studies like that of Liu et al. [2013] argue that spillovers from land-price fluctuations is the major determinant of output and investment movements at business cycle frequencies. Other studies such as Justiniano et al. [2010] stress the importance of investment shocks as a determinant of business cycles. To compare these views within one unified framework, this study introduces land as a collateral asset in investment financing in a standard New Keynesian DSGE model, estimates it, and identifies the major source of U.S. business cycle fluctuations.

The implications are as follows. First, neither housing demand shocks, which is the major determinant of land-price fluctuations, nor MEI shocks are the major source of business cycle fluctuations. Our model suggests that technology shocks are the primary determinant of business cycles. Second, we clarify that the main findings of Liu et al. [2013] crucially depends on the specification of households' utility function. Third, MEI shocks play a minor role in business cycles. Since MEI shocks fail to reproduce business cycle co-movements between output and credits in the model with collateral constraint, they cannot be the principle determinant of business cycles when identified with a model of collateral constraint and credits data.

We raise several caveats. First of all, our model abstracts housing expenditure in construction, following Liu et al. [2013] for the purpose of making comparison easier. This simplification may be justifiable because most of the housing price movements are attributable to the land price movements. However, as suggested in Davis and Heathcote [2007], the importance of housing investments at business cycle frequency is more than

\footnotetext{
${ }^{18}$ To check the robustness of the results, we generate hypothetical data from the baseline model with posterior mean of parameters and execute the same exercise. The variance decompositions are similar in the exercise with actual data and with hypothetical data.
} 
non-negligible. Studies in the model with land prices, residential investments in structure, and collateral constraint are the important subject. Second, our results find that exogenous LTV shocks are also the important factor for output and investment fluctuations, implying that financial intermediaries play a certain role in business cycles. Recent studies such as Justiniano, Primiceri, and Tambalotti [2016] challenge to clarify this role of financial intermediaries in a DSGE model with a housing sector. This line of research is important and promising. Third, we assumed that the collateral constraint always binds. As Guerrieri and Iacoviello [2017] suggest, an occasionally binding constraint creates asymmetric responses and might deliver different results concerning the source of business cycles. This issue is also a promising avenue for future research.

\section{References}

Sungbae An and Frank Schorfheide. Bayesian Analysis of DSGE Models. Econometric Reviews, 26(2-4):113-172, May 2007.

Stephen P. Brooks and Andrew Gelman. General Methods for Monitoring Convergence of Iterative Simulations. Journal of Computational and Graphical Statistics, 7(4):434$455,1998$.

Michal Brzoza-Brzezina and Marcin Kolasa. Bayesian Evaluation of DSGE Models with Financial Frictions. Journal of Money, Credit and Banking, 45(8):1451-1476, December 2013.

Guillermo A. Calvo. Staggered Prices in a Utility-Maximizing Framework. Journal of Monetary Economics, 12:383-398, 1983.

Yongsung Chang and Frank Schorfheide. Labor-supply Shifts and Economic Fluctuations. Journal of Monetary Economics, 50(8):1751-1768, November 2003.

Lawrence J. Christiano, Martin Eichenbaum, and Charles L. Evans. Nominal Rigidities and the Dynamic Effects of a Shock to Monetary Policy. Journal of Political Economy, 113(1):1-45, February 2005.

Lawrence J. Christiano, Roberto Motto, and Massimo Rostagno. Risk shocks. American Economic Review, 104(1):27-65, January 2014.

Morris A. Davis and Jonathan Heathcote. The price and quantity of residential land in the United States. Journal of Monetary Economics, 54(8):2595-2620, November 2007.

Christopher J. Erceg, Dale W. Henderson, and Andrew T. Levin. Optimal monetary policy with staggered wage and price contracts. Journal of Monetary Economics, 46(2):281313 , October 2000.

Luca Guerrieri and Matteo Iacoviello. Collateral constraints and macroeconomic asymmetries. Journal of Monetary Economics, 90(C):28-49, $2017 . \quad$ doi: 10.1016/j.jmoneco.2017.06. 
Gary D. Hansen. Indivisible labor and the business cycle. Journal of Monetary Economics, 16:309-327, 1985.

Yasuo Hirose and Atsushi Inoue. The Zero Lower Bound and Parameter Bias in an Estimated DSGE Model. Journal of Applied Econometrics, 31(4):630-651, 062016.

Matteo Iacoviello. House Prices, Borrowing Constraints, and Monetary Policy in the Business Cycle. American Economic Review, 95(3):739-764, June 2005.

Matteo Iacoviello and Stefano Neri. Housing Market Spillovers: Evidence from an Estimated DSGE Model. American Economic Journal: Macroeconomics, 2(2):125-64, April 2010.

Urban Jermann and Vincenzo Quadrini. Macroeconomic Effects of Financial Shocks. American Economic Review, 102(1):238-71, February 2012.

Alejandro Justiniano, Giorgio E. Primiceri, and Andrea Tambalotti. Investment Shocks and Business Cycles. Journal of Monetary Economics, 57(2):132-145, March 2010.

Alejandro Justiniano, Giorgio E. Primiceri, and Andrea Tambalotti. Investment Shocks and the Relative Price of Investment. Review of Economic Dynamics, 14(1):101-121, January 2011.

Alejandro Justiniano, Giorgio E. Primiceri, and Andrea Tambalotti. A Simple Model of Subprime Borrowers and Credit Growth. American Economic Review, 106(5):543-547, May 2016.

Sohei Kaihatsu and Takushi Kurozumi. Sources of Business Fluctuations: Financial or Technology Shocks? Review of Economic Dynamics, 17(2):224-242, April 2014.

Robert G. King, Charles I. Plosser, and Sergio T. Rebelo. Production, Growth and Business Cycles I. The Basic Neoclassical Model. Journal of Monetary Economics, 21: 195-232, 1988.

Nobuhiro Kiyotaki and John Moore. Credit Cycles. Journal of Political Economy, 105 (2):211-48, April 1997.

Finn E Kydland and Edward C Prescott. Time to Build and Aggregate Fluctuations. Econometrica, 50(6):1345-70, November 1982.

Zheng Liu, Pengfei Wang, and Tao Zha. Land - Price Dynamics and Macroeconomic Fluctuations. Econometrica, 81(3):1147-1184, 052013.

Christopher A. Sims. Macroeconomics and Reality. Econometrica, 48(1):1-48, January 1980.

Frank Smets and Rafael Wouters. Shocks and Frictions in US Business Cycles: A Bayesian DSGE Approach. American Economic Review, 97(3):586-606, June 2007. 
James H. Stock and Mark W. Watson. Business cycle fluctuations in us macroeconomic time series. In J. B. Taylor and M. Woodford, editors, Handbook of Macroeconomics, volume 1 of Handbook of Macroeconomics, chapter 1, pages 3-64. Elsevier, 1999.

V. Wieland, E. Afanasyeva, M. Kuete, and J. Yoo. New methods for macro-financial model comparison and policy analysis. In John B. Taylor and Harald Uhlig, editors, Handbook of Macroeconomics, volume 2, pages 1241 - 1319. Elsevier, 2016. 